Medicine Updates

Faculty of medicine

January 2021, volume 4, issue 4 https://muj.journals.ekb.eg

dean@med.psu.edu.eg

vice_dean_postgraduate@med.psu.edu.eg

DOI: $10.21608 / \mathrm{muj} .2020 .47789 .1033$

ISSN : 2682-2741

Submitted: $26 / 10 / 2020$

Accepted : 31/10/2020

Pages:58- 81

\title{
"Validity Of Right Ventricular Strain In Prediction Of Successful Simple Cardiac Shunt Closure "
}

Dina Abd El Hamid Haroun (Corresponding Author) cardiology department,faculty of medicine,port said university

Laila Mohamed EL-Maghawry, Cardiology department,Faculty of medicine,Zagazig university

Azza Zakaria El Eraky, cardiology department,faculty of medicine,port said university

Mahmoud Shehata Abd El Hamid, cardiology department,faculty of medicine,port said university

Sohil Abdulla Ahmed Elfar. cardiology department,faculty of medicine,port said university

\section{ABSTRACT}

Background: Pulmonary arterial hypertension in congenital heart disease (PAH CHD) is reversed by early shunt closure, but this potential is lost beyond a certain point of no return. this study was conducted to evaluate the results of simple cardiac shunt closure regarding right ventricular function using speckle tracking and reversibility of pulmonary hypertension, testing the ability of echocardiography to provide information with minimal risk, we aimed to detect right ventricular function in simple cardiac shunt patients before closure using longitudinal strain and to investigate its role in predicting reversibility of pulmonary hypertension after closure 
Methods: a prospective randomized comparative study,simple shunt patients from age 25-48 years presented to Zagazig University hospitals, cardiology department from September 2018 to July 2019 were divided into two groups Group I: ten patients having irreversible pulmonary hypertension. Group II: Twenty patients having reversible pulmonary hypertension.

Results: There was statistically significant increase in Group II post closure regarding LVEF, RVFAC,TAPSE, $\mathrm{S}_{\mathrm{RV}}$, RVLS ( $\left.\mathrm{P}<0.05\right)$. While PASP showed significant decrease in Group II post closure $(\mathrm{P}<0.05)$. On the other hand, RVLS was negatively correlated with the defect size $(\mathrm{r}=-0.65 ; \mathrm{p}=<0.001)$, $\mathrm{Qp} / \mathrm{Qs}(\mathrm{r}=-0.53, \mathrm{p}=<0.001)$, PASP $(\mathrm{r}=-0.8, \mathrm{p}=<0.001)$.And significant positive correlation with $\mathrm{S}_{\mathrm{RV}}(\mathrm{r}=0.37 ; \mathrm{p}=<0.001)$, RVFAC $(\mathrm{r}=0.30$, $\mathrm{p}<0.001)$,TAPSE( $\mathrm{r}=0.34, \mathrm{p}<0.001)$. ROC curve analysis revealed that RVLS value of $\geq-20$ could predict reversibility of PASP with AUC 0.9 suggesting strong accuracy $(\mathrm{P}<0.001)$.

Conclusion: The RVLS value of $\geq-20$ could predict reversibility of PASP (P< 0.001). RVLS correctly identify simple shunt patients with increased PASP.

Keywords: Pulmonary hypertension, cardiac shunts, right ventricular strain

\section{INTRODUCTION}

It was found that early shunt closure in congenital heart diseases will lead to reversal of elevated pulmonary artery systolic pressure, so, we should assess reversibility at early stage.

Pulmonary hypertension is diagnosed by increased pulmonary artery pressure ( $\mathrm{m}$ PAP), pulmonary vascular resistance (PVR) and normal pulmonary capillary wedge pressure and clinical presentation of right heart failure (Hoeper et.al.2013).

If pulmonary hypertension became irreversible it cannot be cured but only stabilized by therapy (Van der Feen et.al.2017). 
However, the beneficial effects of shunt closure seem lost after a certain point of no return, after which even accelerated PAH progression may occur months to years after surgery (Van Riel AC et.al.2014).

So, early detection of window of reversibility can be assessed clinically and by measuring heamodynamics (Chiu et.al.2011).

\section{PATIENTS AND METHODS}

From September 2018 to July 2019, (30) patients with simple cardiac shunts were prepared to undergo trans catheter device closure, at echocardiographic and catheterization laboratories Cardiology Department of Zagazig University.

Inclusion criteria were: 1) Significant left-to right shunt (pulmonary-systemic flow ratio > 1.5:1); 2) Shunt-related symptoms: difficult breathing, on exercise, tiredness, leg swelling, rapid heart beats and chest infections.

Exclusion criteria were: 1)ASD with no sufficient rim, ASD near SVC, coronary sinus ;2)Another congenital heart disease ;3)Right-to-left shunt with desaturation $<95 \%$.

We obtained informed consent from all patients in this study according to recommendations of the review board of our faculty.

All patients underwent: 1)history: including age, sex, symptoms of heart failure, shunt related symptoms;2)General and local examination: Blood pressure, pulse ,neck veins, Local examination of the heart for cardiomegaly, pulsations, thrills, heart sounds and murmurs;3)Twelve lead surface ECG: To identify evidence of chamber enlargement, abnormal axis deviation, rate and rhythm disturbances ;4)Echocardiography: is initially performed prior to and 24 hours after percutaneous trans-catheter closure of the shunt an echocardiographic Doppler study, as well as 2D speckle tracking and tissue Doppler imaging of the RV was performed using Vivid 9, General Electric Healthcare (GE Vingmed, Norway) with a harmonic M5S variable-frequency (1.7 -4 MHz) \&M6S phased array transducers.Study performed from subcostal, parasternal and apical windows and the patient is connected to single lead ECG.5)percutaneous shunt closure : In all 
patients after antibiotic prophylaxis, general anesthesia and sterilization, arterial and venous access were gained using the seldinger's technique, the right or left femoral artery and vein were accessed and 5-6 F sheath was introduced into the artery and $6 \mathrm{~F}$ sheath was introduced into the vein.

After the artery was accessed $100 \mathrm{IU} / \mathrm{Kg}$ heparin were administrated intravenously (Crystal et.al.2015) then device implantation was done and the patient stays in hospital overnight for post device observation and discharged home the following day. Prior to the discharge a physical examination, a TTE, ECG and a chest radiograph performed to assess the device and to look for any potential complication.

\section{Statistical analysis}

All patients' data were collected, checked and analyzed by using (SPSS version 20). Data were collected as mean \pm standard deviation (SD) and number with (\%) according to type of variable. Chi-square test $\left(\chi^{2)}\right.$, receiver operator curve (ROC) Correlation and regression analysis were used to determine the relation between RVLS and other echo parameters. $\mathrm{P}$ value $<0.05$ was considered significant.

\section{$\underline{\underline{\text { RESULTS }}}$}

The study included 30 patients with simple cardiac shunts the studied patients were 23 females (76.6\%) and 7 males (23.4\%), with average age of $37.3 \pm 7$ years. Fourteen patients had ASD (46.6\%), 10 had VSD (33.4\%) and 6 had PDA (20\%), with defect size ranged from 10-22 with mean 16. $8 \pm 3.6$ SD. QP/QS ranged from 1.9-3.3 with mean was 2.6 \pm 0.4 SD. PASP ranged from 40-69 with mean 54.5 $\pm 8.8 \mathrm{SD}$. Our patients were classified into two groups according to reversibility of pulmonary hypertension post closure where decrease of mPAP $\geq 10 \mathrm{mmHg}$ to reach an absolute value of $\mathrm{mPAP} \leq 40 \mathrm{mmHg}$ is considered reversible (6):Group I: ten patients, 4 males (13.3\%) and 6 females (20\%) with mean age $39 \pm 6.9$ years were having irreversible pulmonary hypertension. Group II: Twenty patients, 3 males (10\%) and 17 females (56.7\%) with mean age $36.5 \pm 7.3$ years were having reversible pulmonary hypertension .There was no 
significant difference between two categories regarding age and sex (P> 0.05).(Table1) Defect size was $19.8 \pm 1.6 \mathrm{~mm}$ in group I as compared to $15.3 \pm 7.5$ $\mathrm{mm}$ in group II with significant increase in GI $(\mathrm{P}<0.001)$. Also, QP/QS was $2.96 \pm 0.2$ in group I as compared to $2.5 \pm 0.4$ in group II with significant increase in GI (P0.003) .(Table 1)

\begin{tabular}{|c|c|c|c|c|c|}
\hline & & $\begin{array}{c}\text { Group(I) } \\
\text { n. }=10\end{array}$ & $\begin{array}{c}\text { Group (II) } \\
\text { n }=20\end{array}$ & $1 / x^{t}$ & P-value \\
\hline \multirow[t]{2}{*}{ Age(years) } & $\overline{\mathbf{X}} \pm \mathrm{SD}$ & $39 \pm 6.9$ & $36.5 \pm 7.3$ & \multirow{2}{*}{0.89} & \multirow{2}{*}{0.32} \\
\hline & (Range) & $29-48$ & $25-48$ & & \\
\hline \multirow[t]{2}{*}{ Defect size } & $\begin{array}{l}\overline{\mathbf{X}} \pm \\
\mathrm{SD}\end{array}$ & $19.8 \pm 1.6$ & $15.3 \pm 7.5$ & \multirow[t]{2}{*}{3.8} & \multirow[t]{2}{*}{$<0.001 * *$} \\
\hline & (Range) & $17-22$ & $10-22$ & & \\
\hline \multirow[t]{2}{*}{ Qp/Qs } & $\overline{\mathbf{X}} \pm \mathrm{SD}$ & $2.96 \pm 0.2$ & $2.5 \pm 0.4$ & \multirow{2}{*}{3.19} & \multirow{2}{*}{$0.003 *$} \\
\hline & (Range) & $2.7-3.3$ & 1.9-3.3 & & \\
\hline \multirow{2}{*}{$\begin{array}{c}\text { Gender }(n, \% \\
)\end{array}$} & M & $4(57.0)$ & $3(42.8)$ & \multirow{2}{*}{ O.O } & \multirow{2}{*}{0.65} \\
\hline & $\mathbf{F}$ & $6(26.0)$ & $17(73.9)$ & & \\
\hline
\end{tabular}

ASD: atrial septal defect, VSD: ventricular septal defect, PDA: patent ductus Arteriosus, $\boldsymbol{\eta}$ : number, \%: percentage.

The LVEF showed significant increase in reversible cases after catheter closure.For the RV dimensions: there is significant increase in RVFAC in reversible cases after catheter closure. TAPSE showed non significant increase in reversible cases after closure. PASP showed significant decrease in reversible cases after interventional closure (Table 2).Tissue Doppler tricuspid annular velocity showed insignificant increase in reversible cases post closure (Table 2).

Table (2): Changes in EF according to reversibility

\begin{tabular}{|l|c|c|c|c|c|}
\hline EF & Group I & Group II & t & P-value \\
\hline \multirow{2}{*}{ Pre } & $\overline{\mathrm{X}} \pm \mathrm{SD}$ & $58.2 \pm 2.3$ & $58.6 \pm 2.1$ & \multirow{2}{*}{0.47} & 0.63 \\
\cline { 2 - 6 } & (Range) & $55-61$ & $55-61$ & & \\
\hline \multirow{2}{*}{ Post } & $\overline{\mathrm{X}} \pm \mathrm{SD}$ & $59.2 \pm 2.1$ & $63.3 \pm 2.3$ & \multirow{2}{*}{5.6} & $<0.001^{* *}$ \\
\cline { 1 - 5 } & (Range) & $56-62$ & $61-67$ & & \\
\hline
\end{tabular}

$\mathbf{E F}$ : ejection fraction, $\mathbf{p}<0.05$ is significant, *statistically significant, $\%$ : percentage. 
After closing of the defect, longitudinal RV strain increased significantly (Table 3).

Table (3): Changes in RVFAC, TAPSE, PASP\& $\mathrm{S}_{\mathrm{RV}}$ According To Reversibility.

\begin{tabular}{|c|c|c|c|c|c|}
\hline \multicolumn{2}{|l|}{ RVFAC } & Group I & Group II & $\mathrm{t}$ & Prvalue \\
\hline \multirow[t]{2}{*}{ Pre } & $\overline{\mathrm{X}} \pm \mathrm{SD}$ & $\begin{array}{c}38.8 \pm \\
9.5\end{array}$ & $38.6 \pm 6.7$ & \multirow{2}{*}{1.68} & \multirow{2}{*}{0.86} \\
\hline & (Range) & $32-40$ & $36-44$ & & \\
\hline \multirow[t]{2}{*}{ Post } & $\overline{\mathrm{X}}_{ \pm \mathrm{SD}}$ & $40.3 \pm 5.0$ & $41.3 \pm 7.1$ & \multirow{2}{*}{0.14} & \multirow{2}{*}{0.1} \\
\hline & (Range) & $28-34$ & $43-51$ & & \\
\hline \multicolumn{2}{|l|}{ P-value } & $0.01^{*}$ & $0.01 *$ & & \\
\hline \multicolumn{6}{|l|}{ TAPSE } \\
\hline \multirow[t]{2}{*}{ Pre } & $\begin{array}{l}\overline{\mathrm{X}}_{ \pm} \\
\mathrm{SD}\end{array}$ & $2.2 \pm 1.8$ & $2.5 \pm 1.6$ & \multirow[t]{2}{*}{0.03} & \multirow[t]{2}{*}{0.87} \\
\hline & (Range) & $12-18$ & $21-25$ & & \\
\hline \multirow[t]{2}{*}{ Post } & $\overline{\mathrm{X}} \pm \mathrm{SD}$ & $2.5 \pm 0.9$ & $2.6 \pm 0.5$ & \multirow{2}{*}{0.79} & \multirow{2}{*}{$<0.06$} \\
\hline & (Range) & $13-19$ & $23-27$ & & \\
\hline \multicolumn{2}{|l|}{ P-value } & $0.01 *$ & 0.9 & & \\
\hline \multicolumn{6}{|l|}{ PASP } \\
\hline \multirow[t]{2}{*}{ Pre } & $\begin{array}{l}\overline{\mathrm{X}} \\
\pm \mathrm{SD}\end{array}$ & $\begin{array}{c}51.4 \\
\pm 16.3\end{array}$ & $50.4 \pm 15.5$ & \multirow[t]{2}{*}{7.4} & \multirow[t]{2}{*}{0.9} \\
\hline & (Range) & $60-68$ & $42-54$ & & \\
\hline \multirow[t]{2}{*}{ Post } & $\begin{array}{l}\overline{\mathrm{X}}_{ \pm} \\
\mathrm{SD}\end{array}$ & $48.0 \pm 4$ & $37.3 \pm 2.7$ & \multirow[t]{2}{*}{12.9} & \multirow[t]{2}{*}{$<0.01^{* *}$} \\
\hline & (Range) & $59-67$ & $37-43$ & & \\
\hline \multicolumn{2}{|l|}{ P-value } & 0.8 & $<0.001 * *$ & & \\
\hline \multicolumn{6}{|l|}{$\mathrm{S}_{\mathrm{RV}}$} \\
\hline \multirow[t]{2}{*}{ Pre } & $\overline{\mathrm{X}} \pm \mathrm{SD}$ & $13.4 \pm 3.0$ & $13.7 \pm 2.8$ & \multirow{2}{*}{8.4} & \multirow{2}{*}{0.08} \\
\hline & (Range) & $9-13$ & $12-16$ & & \\
\hline \multirow[t]{2}{*}{ Post } & $\overline{\mathrm{X}} \pm \mathrm{SD}$ & $14.1 \pm 2.6$ & $14.0 \pm 2.8$ & \multirow{2}{*}{6.4} & \multirow{2}{*}{$<0.001^{* *}$} \\
\hline & (Range) & $9-13$ & $12-18$ & & \\
\hline \multicolumn{2}{|l|}{ P-value } & 0.9 & 0.8 & & \\
\hline
\end{tabular}

RVFAC: right ventricular fractional area changes, $\mathbf{p}<0.05$ is significant, *statistically significant, $\%$ : percentage. 
TAPSE: tricuspid annular plane systolic excursion, $\mathbf{p}<0.05$ is significant, *statistically significant, $\%$ : percentage.

PASP: pulmonary artery systolic pressure, $\mathbf{p}<0.05$ is significant, *statistically significant

$\mathbf{S}_{\mathbf{R V}}$ : systolic tricuspid tissue Doppler imaging annular velocity, $\mathbf{p}<0.05$ is significant, $*$ Statistically significant, $\%$ : percentage.

RVLS was negatively correlated with the defect size $(\mathrm{r}=-0.65 ; \mathrm{p}=<0.001)$, Qp/Qs $(r=-0.53, p=<0.001)$, PASP $(r=-0.8, p=<0.001)$.On other hand, It revealed significant positive correlation with $S_{R V}(r=0.37 ; p=<0.001)$ RVFAC $(\mathrm{r}=0.30,<0.001)$, TAPSE $(\mathrm{r}=0.34,<0.001)($ Table 4$)$.

Table (4): Changes in RVLS according to reversibility

\begin{tabular}{|l|c|c|c|c|c|}
\hline RVLS & & Group(I) & Group(II) & t & P-value \\
\hline \multirow{2}{*}{ Pre } & $\overline{\mathrm{x}} \pm \mathrm{SD}$ & $-20.8 \pm 8.6$ & $24.9 \pm 2.1$ & \multirow{2}{*}{3.5} & $<0.01^{* *}$ \\
\cline { 2 - 5 } & (Range) & $15-19$ & $23-27$ & & \\
\hline \multirow{2}{*}{ Post } & $\overline{\mathrm{x}} \pm \mathrm{SD}$ & $-21.3 \pm 8.5$ & $-25.6 \pm 5.5$ & \multirow{2}{*}{2.1} & $<0.001^{* *}$ \\
\cline { 2 - 5 } & (Range) & $15-19$ & $24-30$ & & \\
\hline P-value & & 0.8 & 0.9 & & \\
\hline
\end{tabular}

RVLS: right ventricular longitudinal strain, p>0.05 is significant, *statistically significant , \%: percentage.

ROC curve analysis revealed that the RVLS value of -20 could predict reversibility of PASP with AUC 0.9 suggesting strong accuracy $(\mathrm{P}<0.001)$. RVLS correctly identify simple shunt patients with increased PASP (sensitivity $80 \%$ ), and it correctly reports $85 \%$ of simple shunt patients without increased PASP as true negatives, while $15 \%$ are incorrectly identified as false positive with specificity $85 \%$ (Table6),(Fig1).

Table (5): Correlation between RVLS and Other Parameters:

\begin{tabular}{|l|c|c|c|}
\hline & $\mathbf{R}$ & P-value & sign \\
\hline AGE & 0.26 & $>0.05$ & NS \\
\hline DEFECT SIZE & -0.65 & $<0.001^{* *}$ & HS \\
\hline Qp/Qs & -0.53 & $<0.001^{* *}$ & HS \\
\hline EF & 0.04 & $>0.05$ & NS \\
\hline RVFAC & 0.30 & $<0.001^{* *}$ & S \\
\hline TAPSE & 0.34 & $<0.001^{* *}$ & S \\
\hline PASP & -0.80 & $<0.001^{* *}$ & HS \\
\hline S $_{\text {Rv }}$ & 0.37 & $<0.001^{* *}$ & HS \\
\hline
\end{tabular}

The logistic regression analysis detected that the RVLS, RVFAC, SRV were 
independent predictors of reversibility of pulmonary hypertension $(\mathrm{P}<0.05)$ (Table7)

Table (6): Validity of RV Strain in Predicting Reversibility of PH:

\begin{tabular}{|l|c|c|l|c|c|c|}
\hline Cutoff & Sensitivity & Specificity & $\begin{array}{c}\text { PV } \\
+\mathrm{VE} \text { - VE }\end{array}$ & Accuracy & AUC & P-value \\
\hline $\mathbf{2 - 2 0 . 0}$ & $80.0 \%$ & $85.0 \%$ & $\begin{array}{l}72.7 \% \\
89.5 \%\end{array}$ & $83.3 \%$ & 0.9 & $<0.001^{* *}$ \\
\hline
\end{tabular}

Table (7): Independent predictors of Reversibility of PASP:

\begin{tabular}{|c|c|c|c|}
\hline & B \pm SE & 95\%CL & P-value \\
\hline RVFAC & $0.31 \pm 0.17$ & $0.03-0.66$ & $0.03^{*}$ \\
\hline S $_{\text {Rv }}$ & $0.33 \pm 0.18$ & $0.04-0.69$ & $0.02^{*}$ \\
\hline RVLS & $0.28 \pm 0.006$ & $0.11-0.44$ & $<0.001^{* *}$ \\
\hline
\end{tabular}

ROC Curve

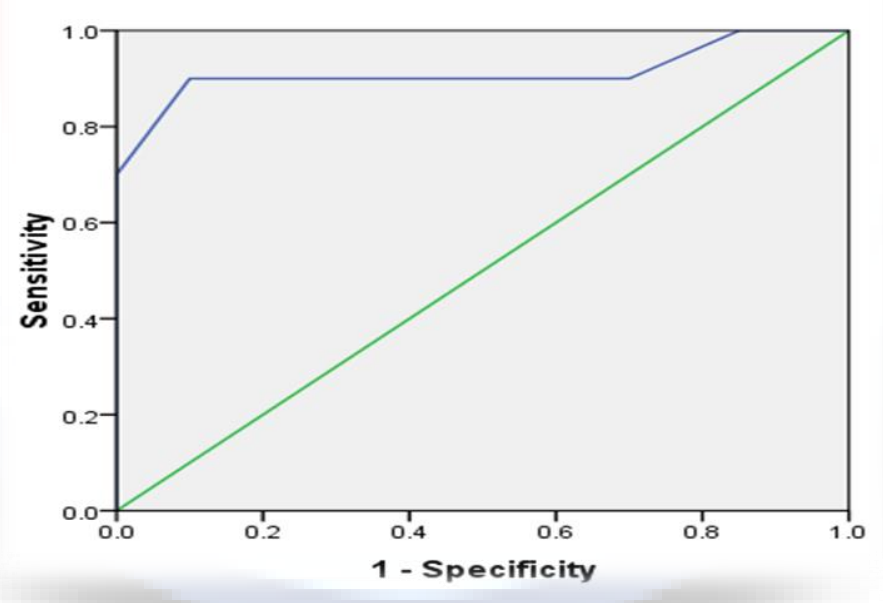

Figure (1): ROC of RV Strain in Prediction Reversibility of PH 


\section{Case Demonstration}

\section{Demographic and Clinical Data:}

\section{Complete history taking:}

- Age: 16 years old

- Sex: female patient

- Clinical presentation: Admitted with exertion dyspnea with ordinary effort.

- NYHA: II.

2. General and local examination: BSA: $0.22 \mathrm{~m} 2$

3. ECG: Normal sinus rhythm, right axis deviation

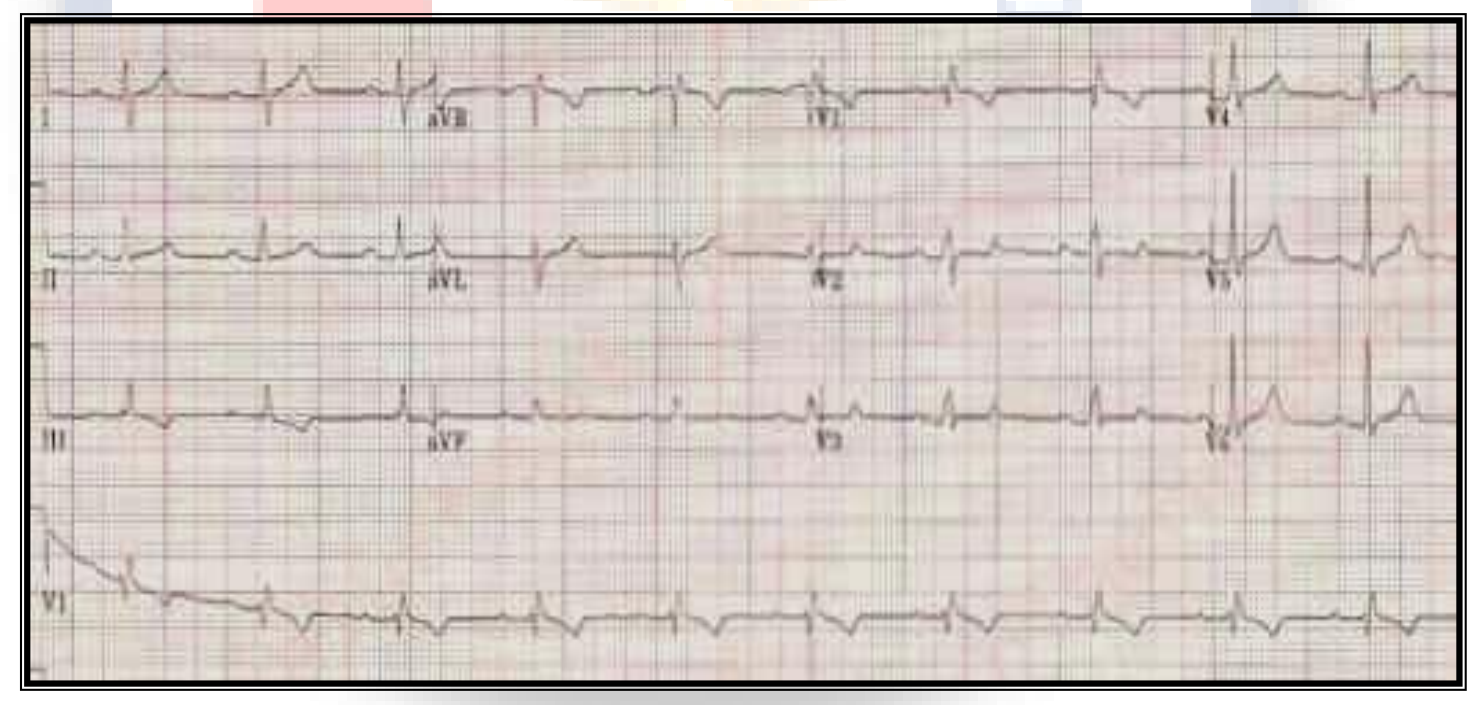

Figure (A): Normal sinus rhythm, right axis deviation

\section{ECHO}

\section{A) Conventional echocardiography}

Native ASD diameter: $20 \mathrm{~mm}$. 


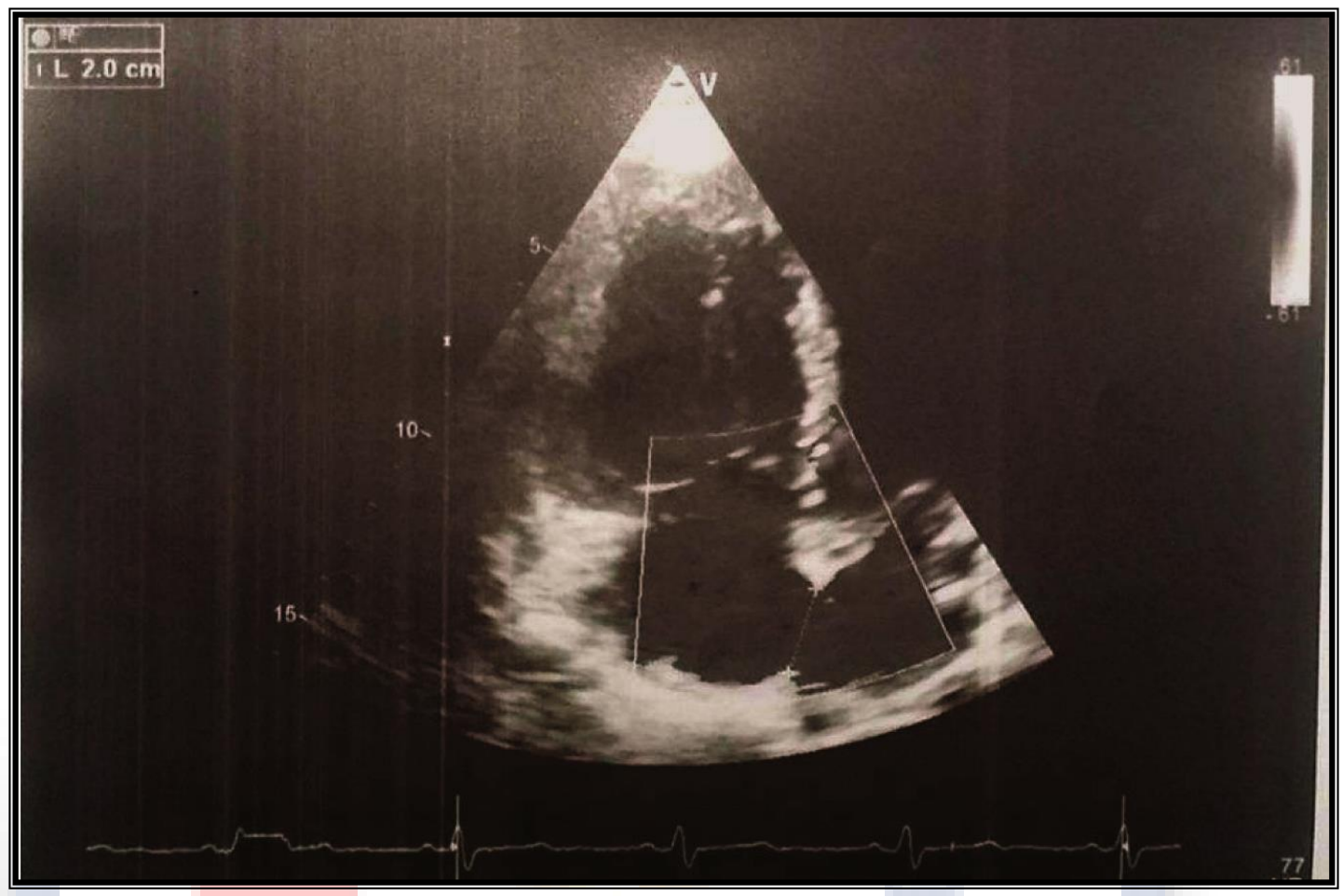

Figure (B): apical 4-chamber show ASD

QP/QS: 3.3

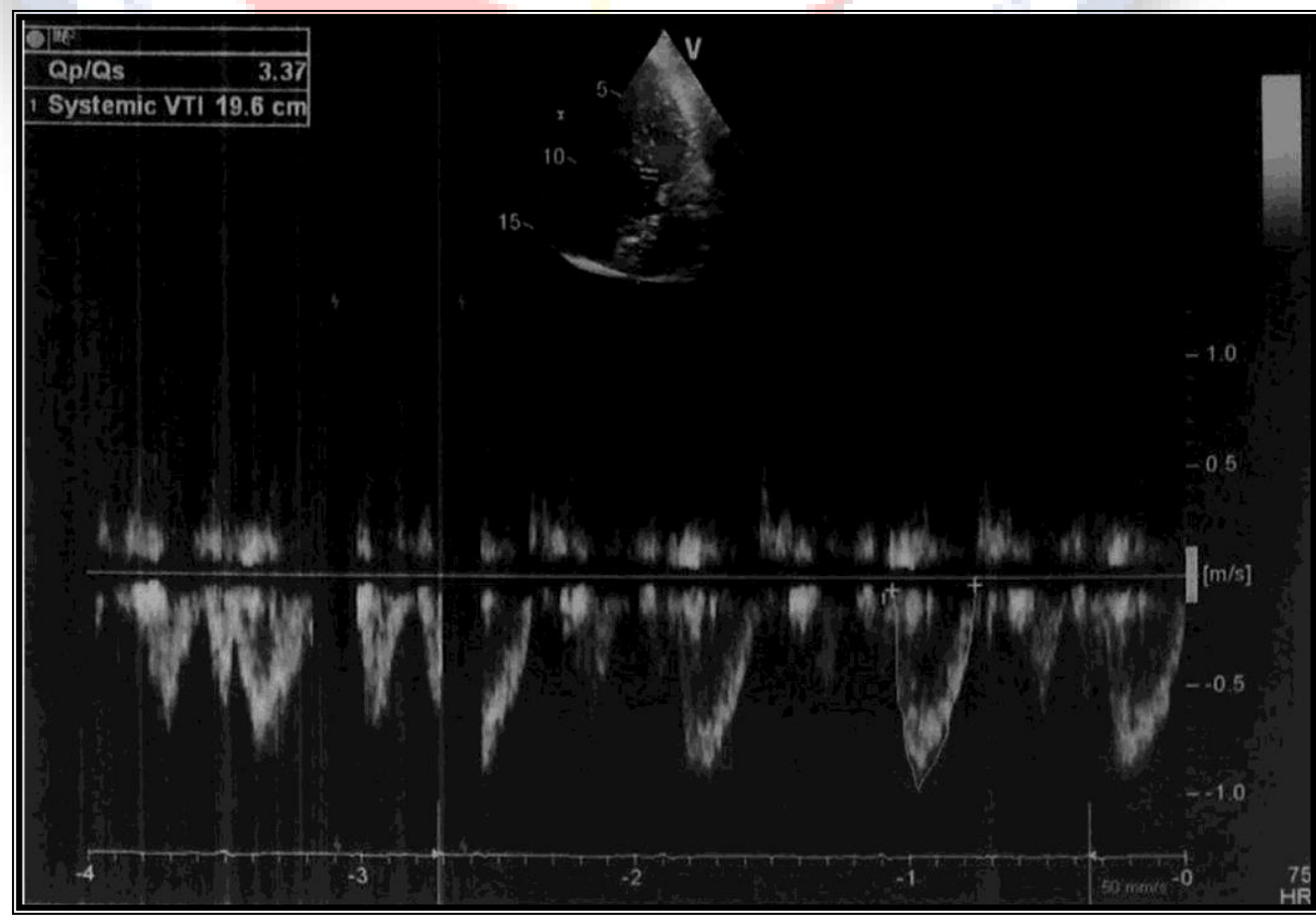

Figure (C): show QP:QS 


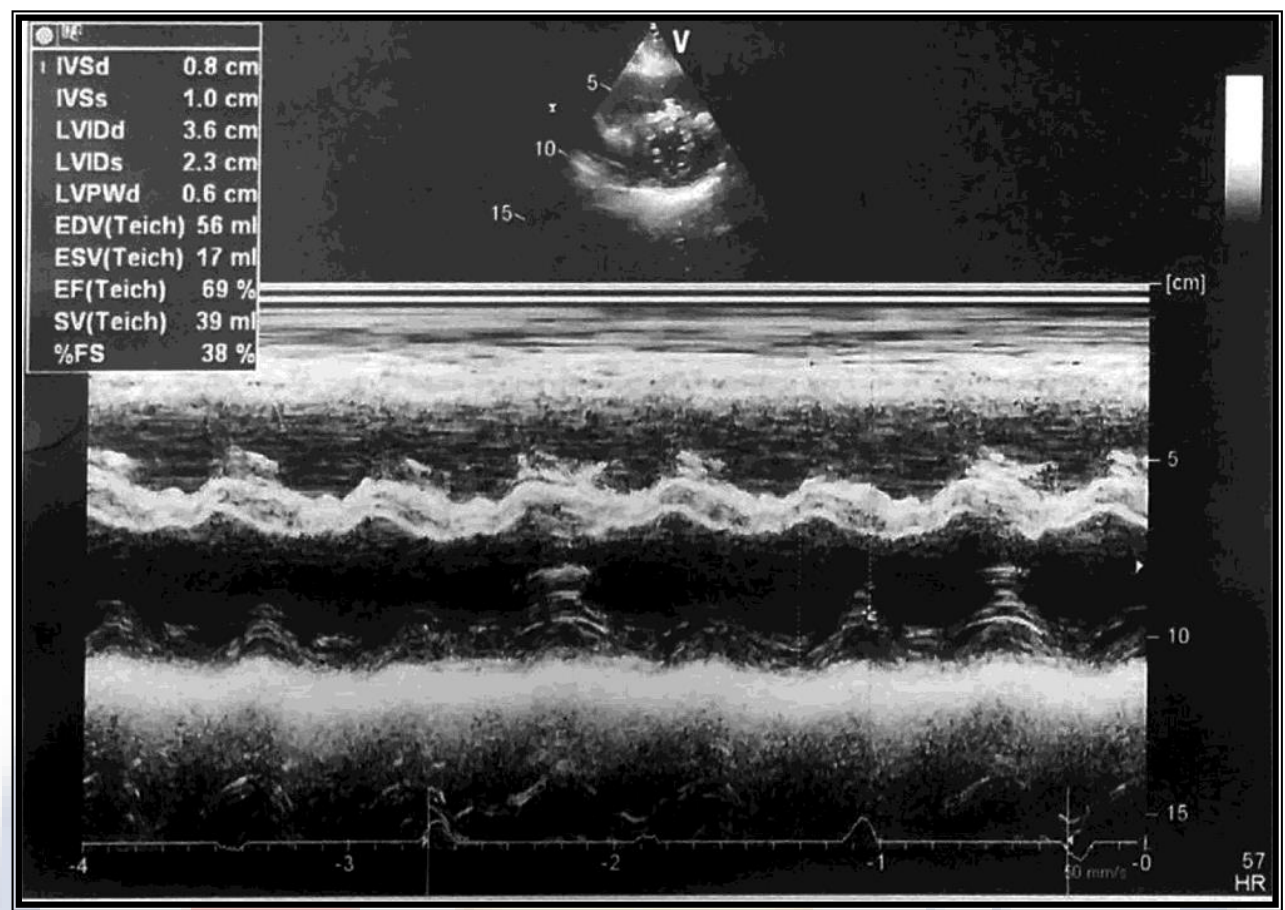

Figure (D): Baseline M-mode of LV (EF: $69 \%$ )

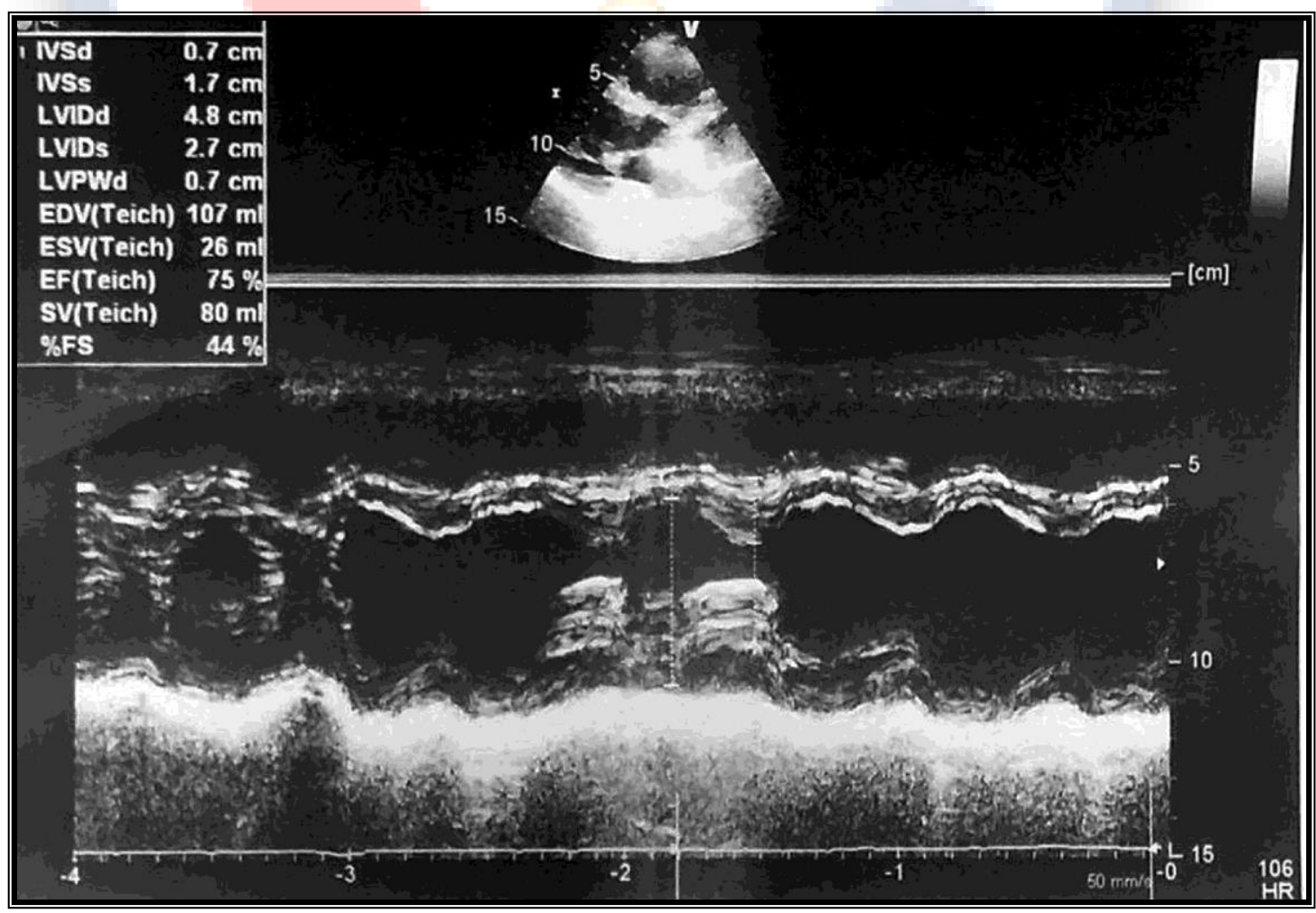

Figure (E): M-mode of LV after closure (EF: $75 \%$ ) 


\section{RVFAC:}

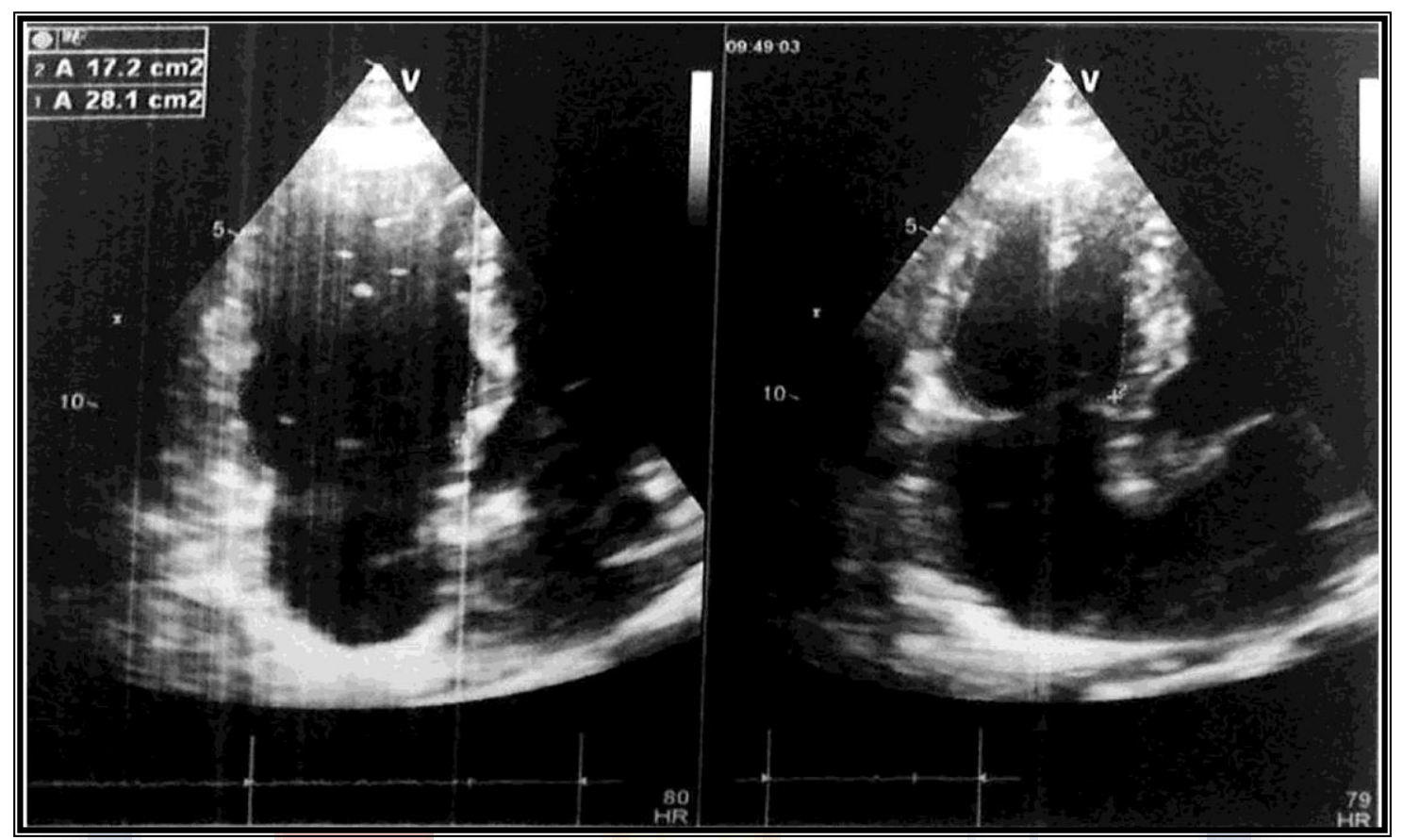

Figure (F): RVFAC before closure: $39 \%$

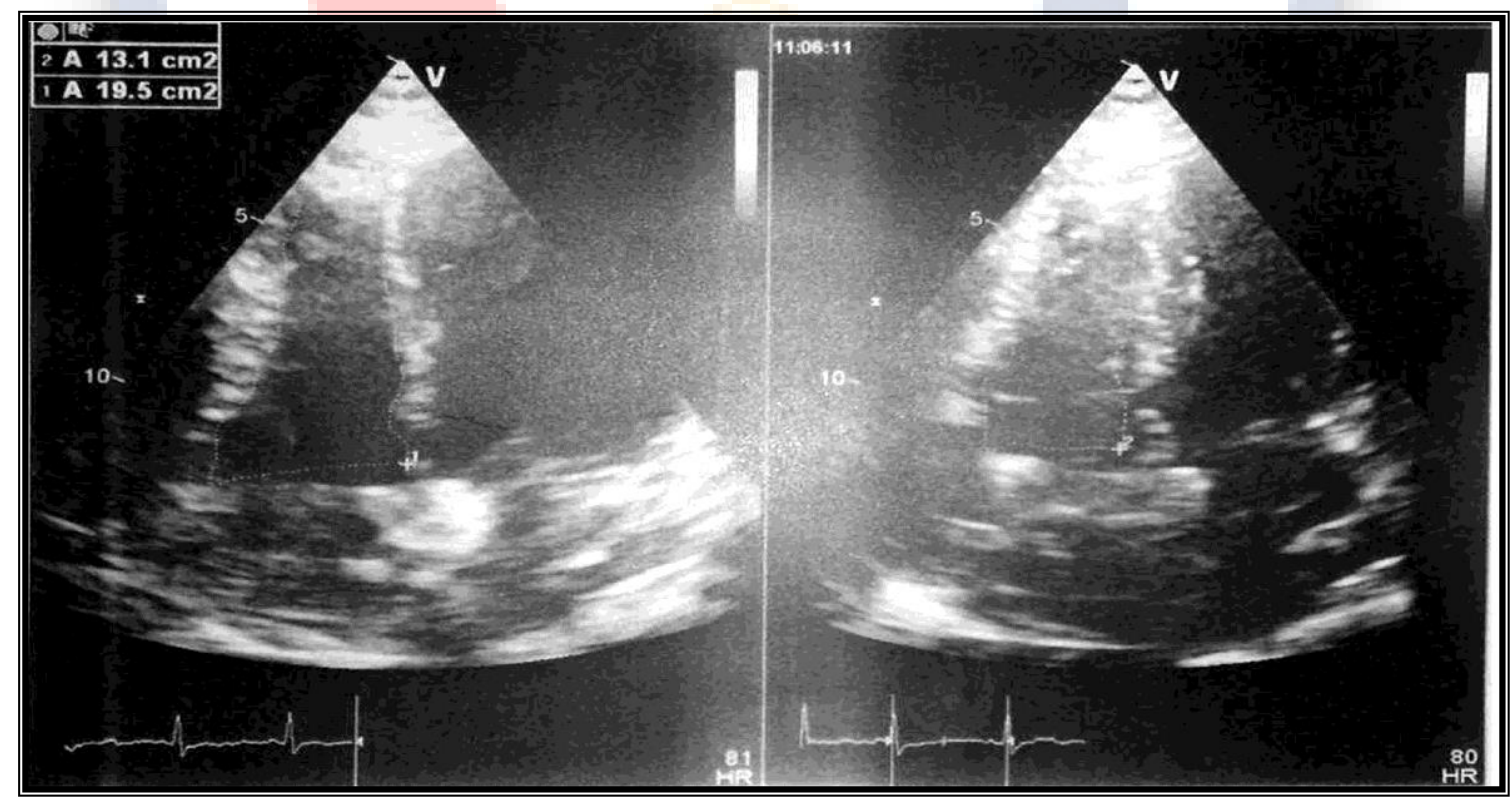

Figure (G): RVFAC after closure: $\mathbf{3 2 . 8} \%$ 


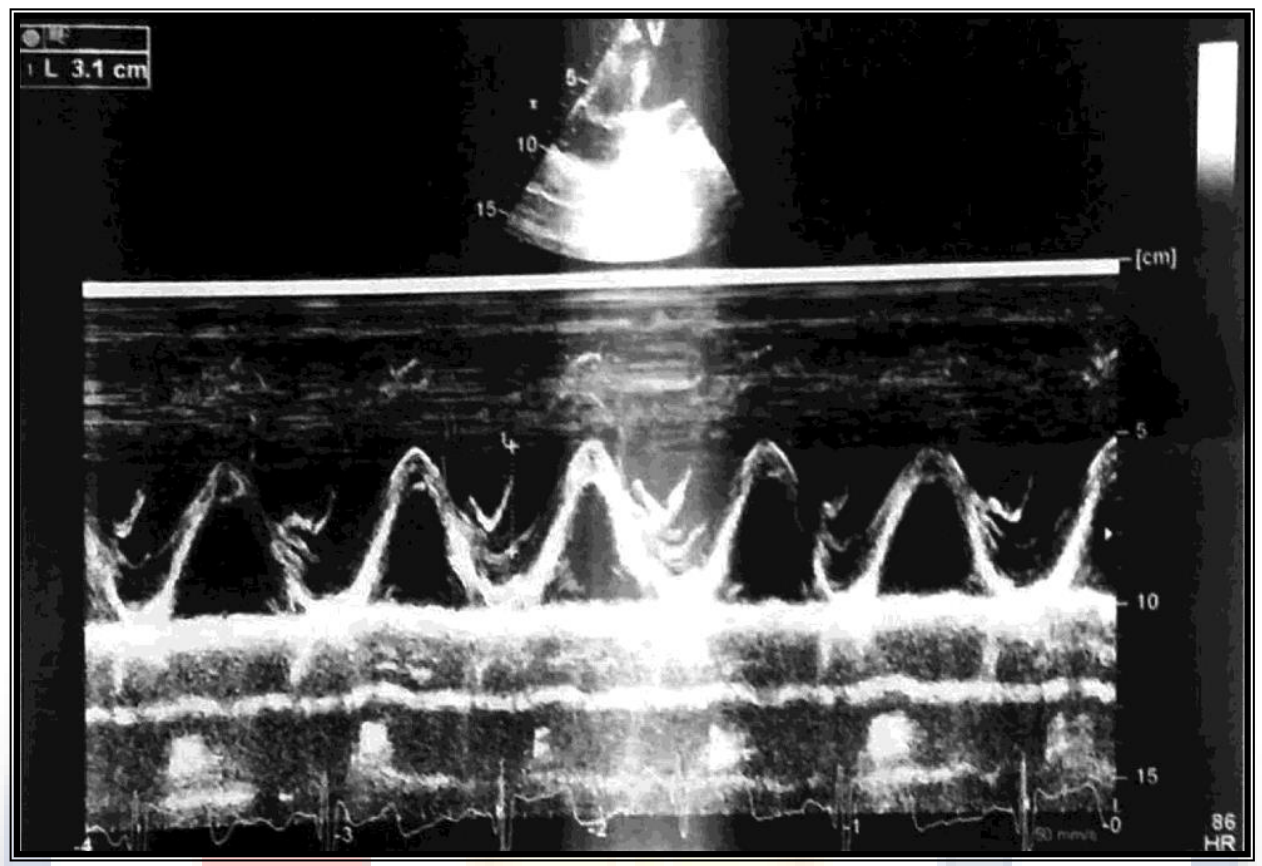

Figure (H): TAPSE before closure: $31 \mathrm{~mm}$

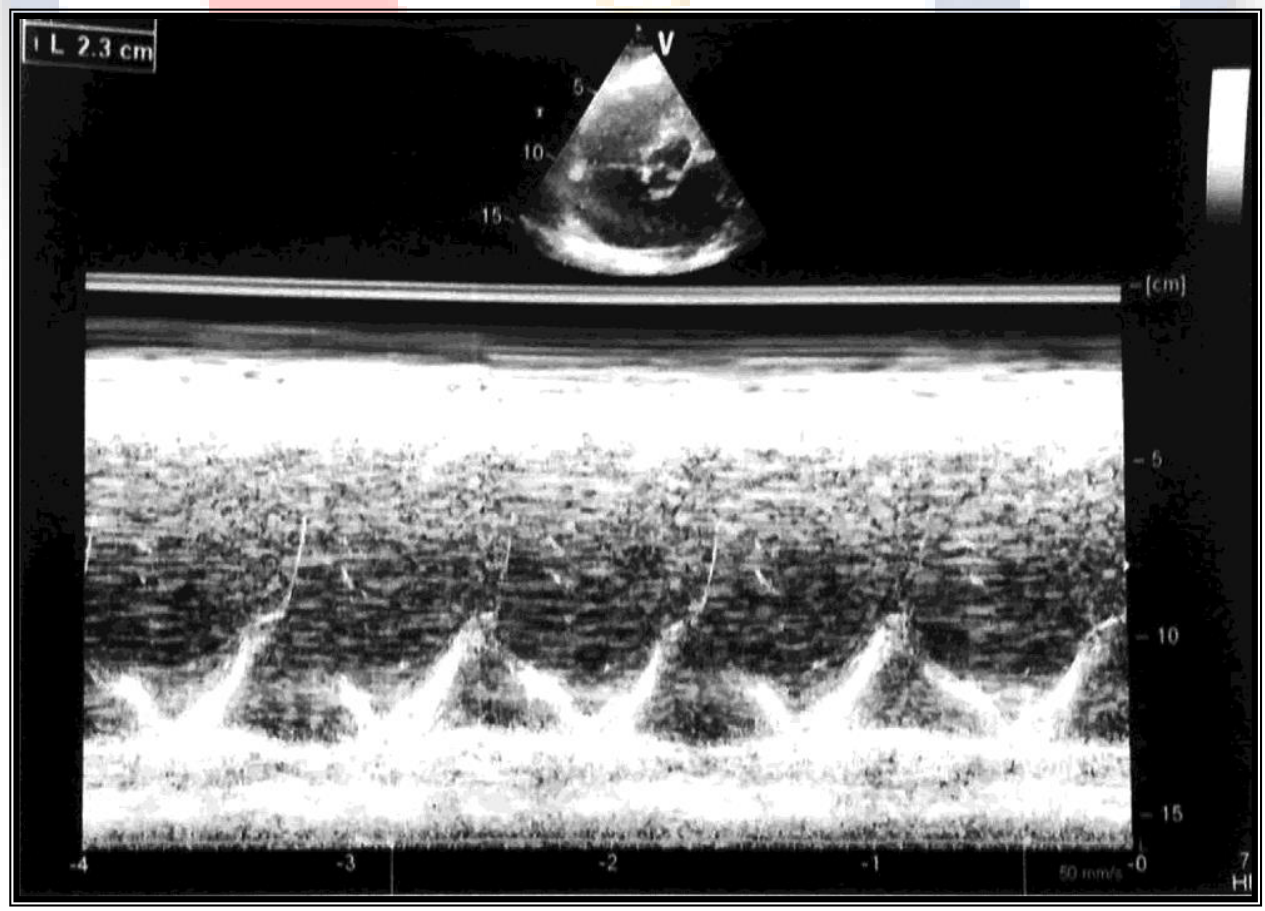

Figure (I): TAPSE after closure: $23 \mathrm{~mm}$ 


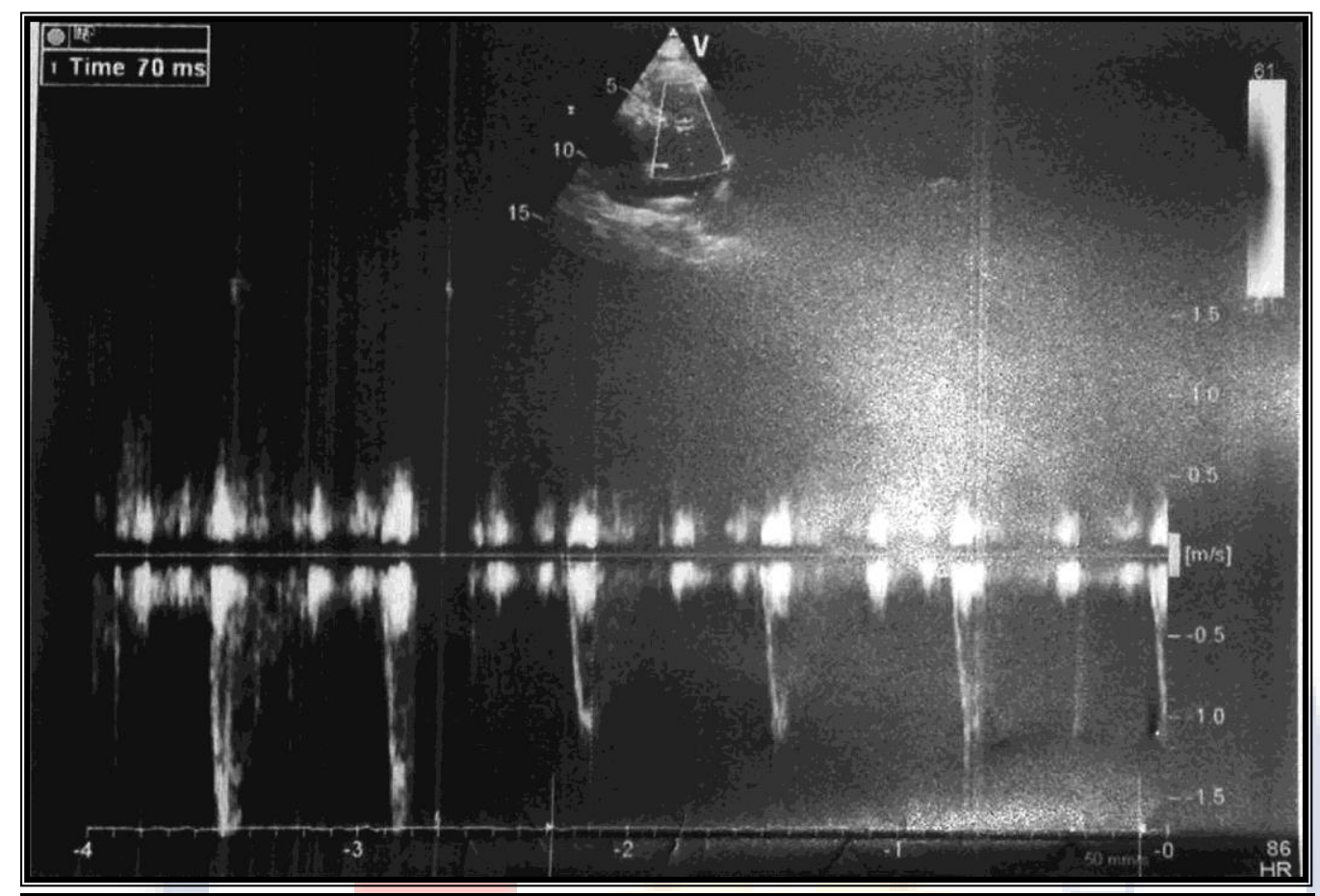

Figure (J): PSAP before closure $45 \mathrm{mmHg}$

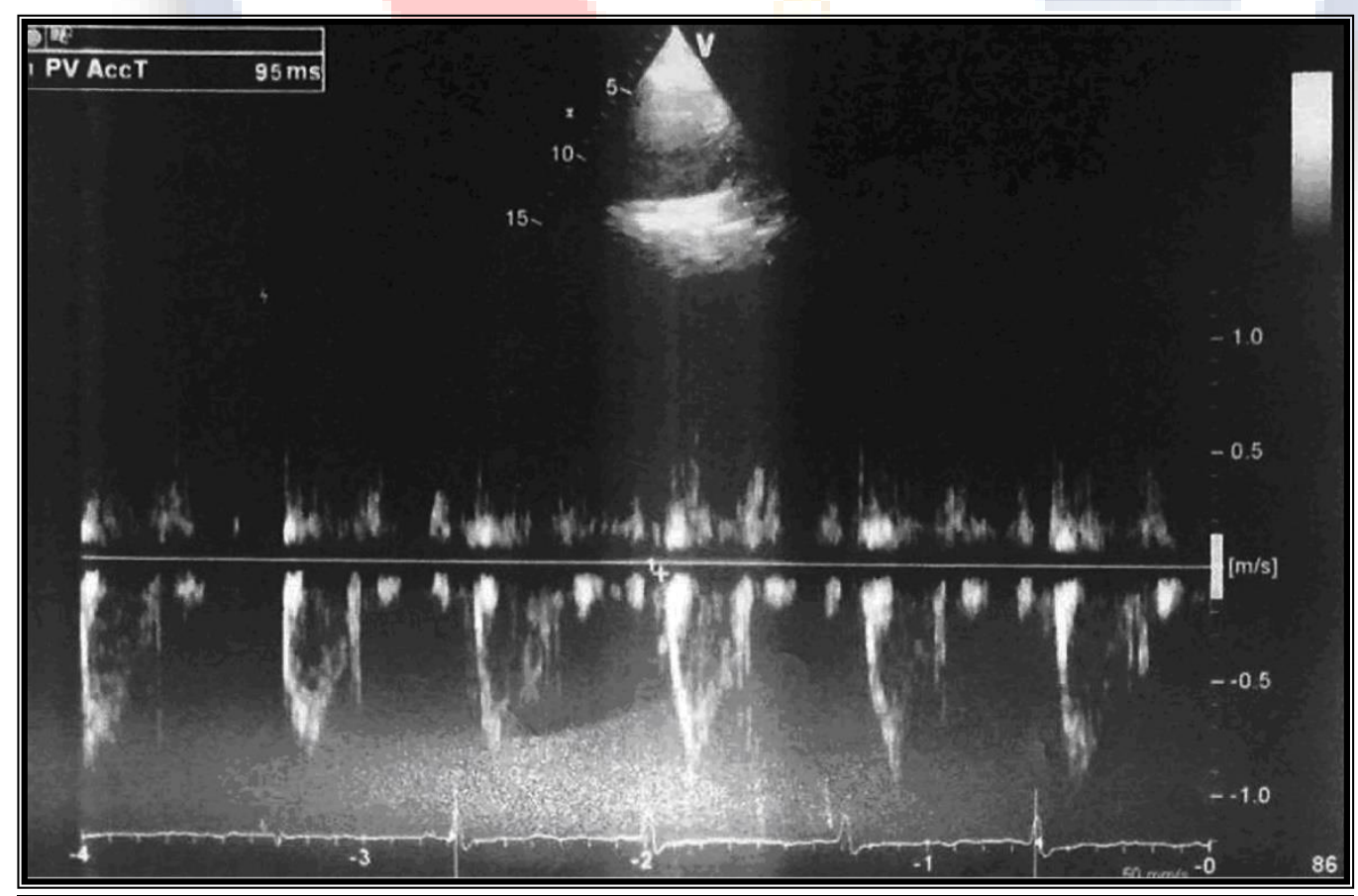

Figure (K): PSAP After closure: $\mathbf{3 2} \mathbf{~ m m H g}$ 


\section{B) Tissue Doppler imaging (TDI)}

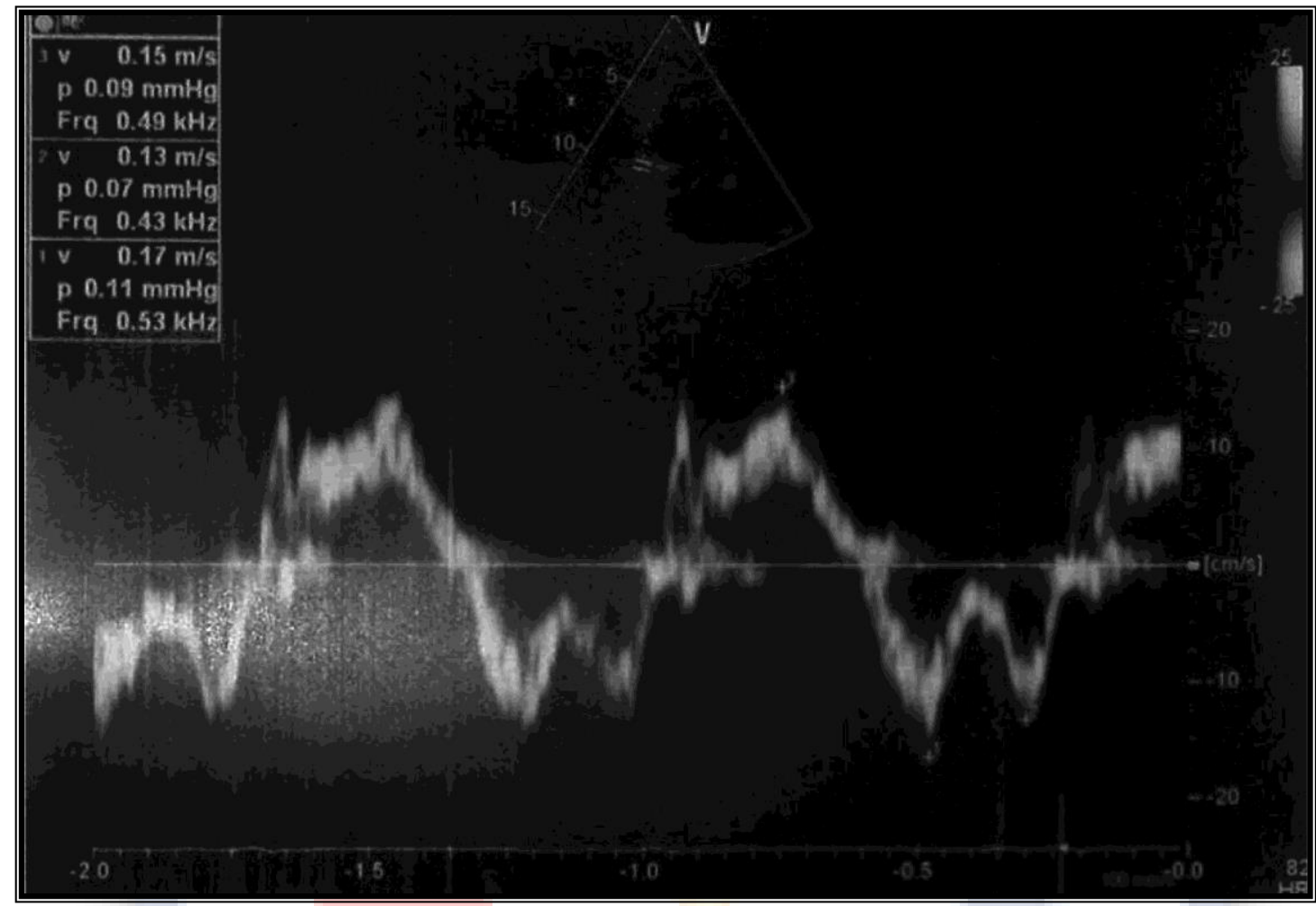

Figure (L): Before: $15 \mathrm{~cm} / \mathrm{s}$

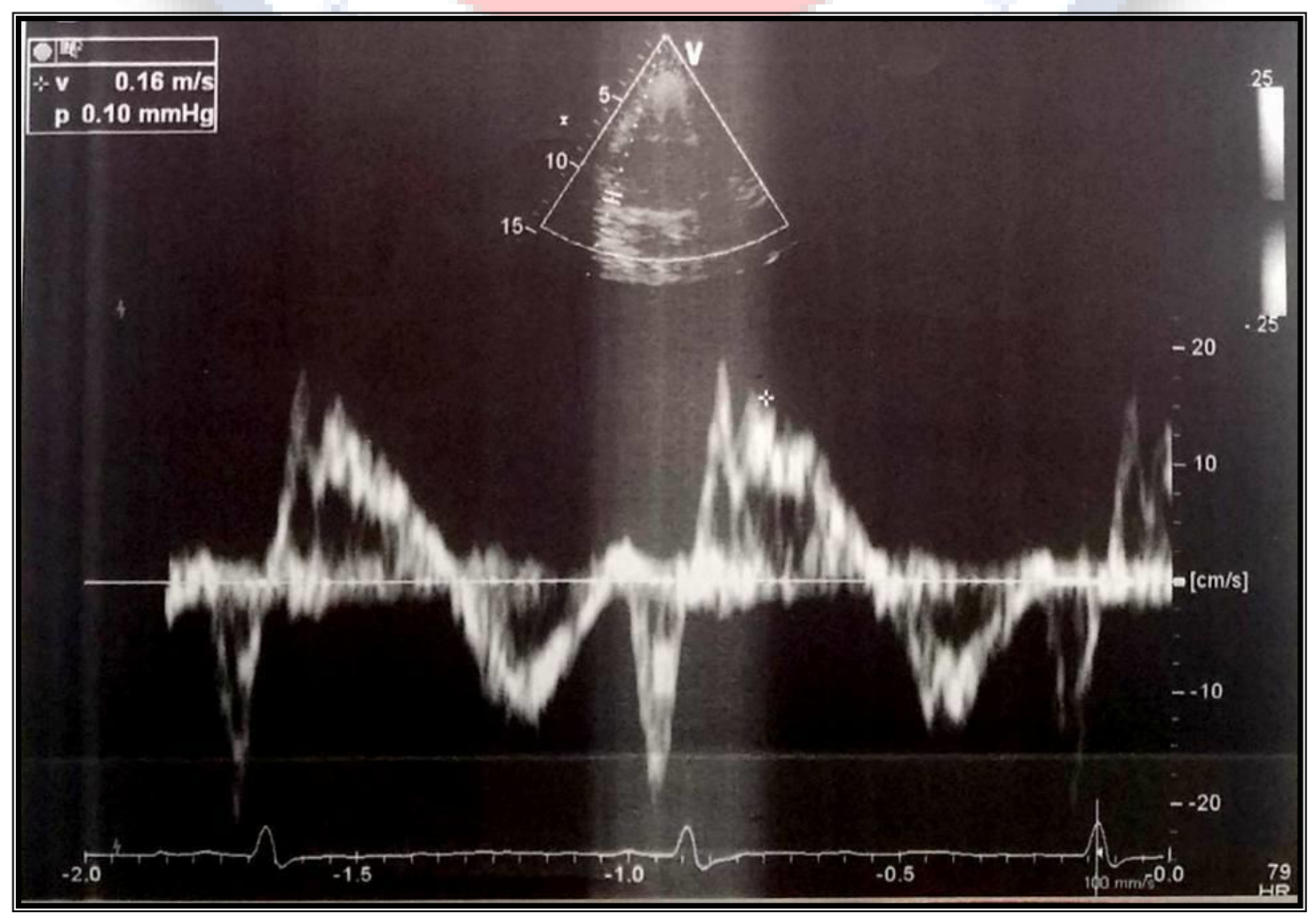

Figure (M): After: $16 \mathrm{~cm} / \mathrm{s}$ 
Two-dimensional speckle tracking echocardiography (2D strain)

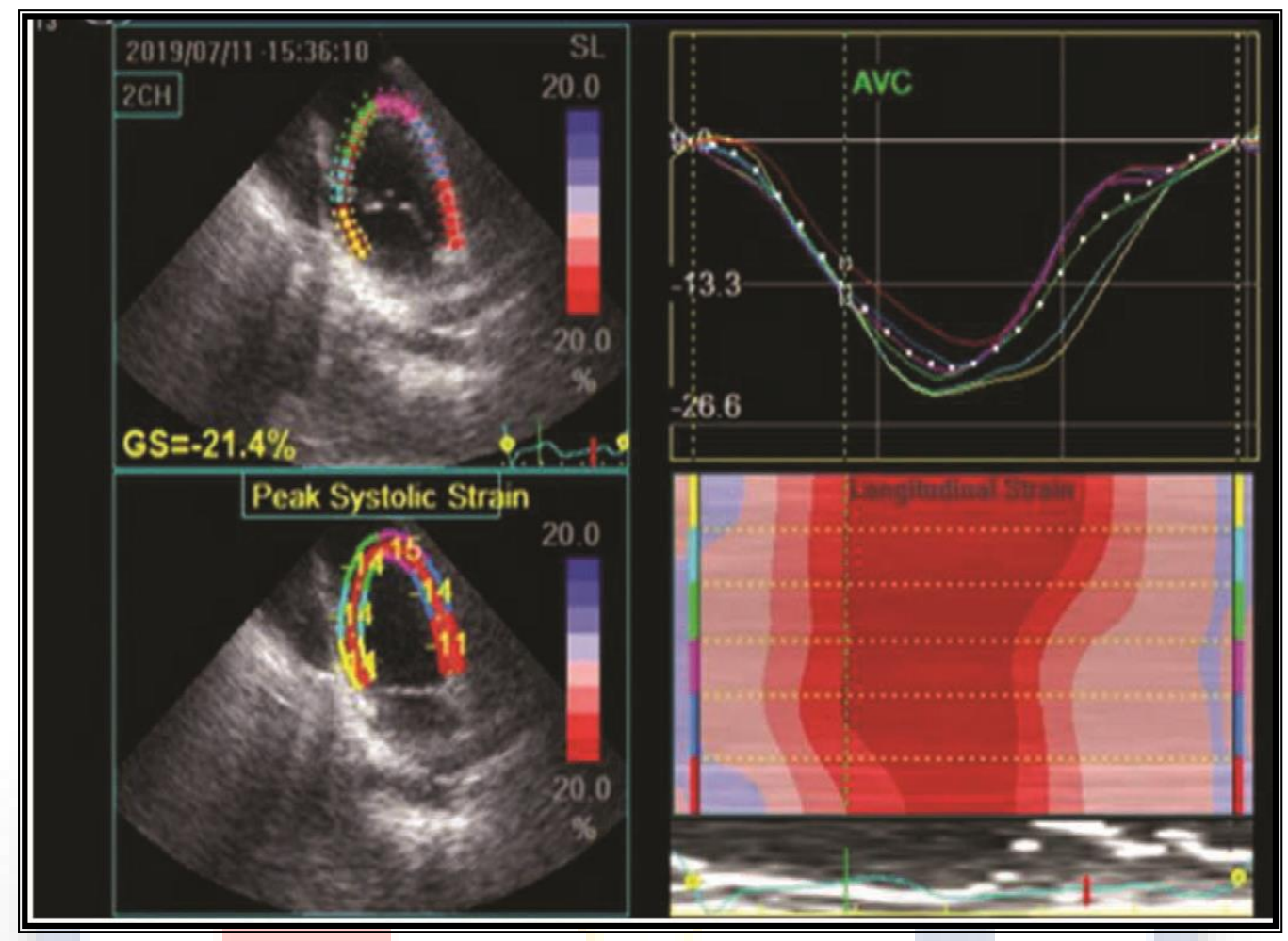

Figure (N): Before: $-\mathbf{2 1 . 4} \%$

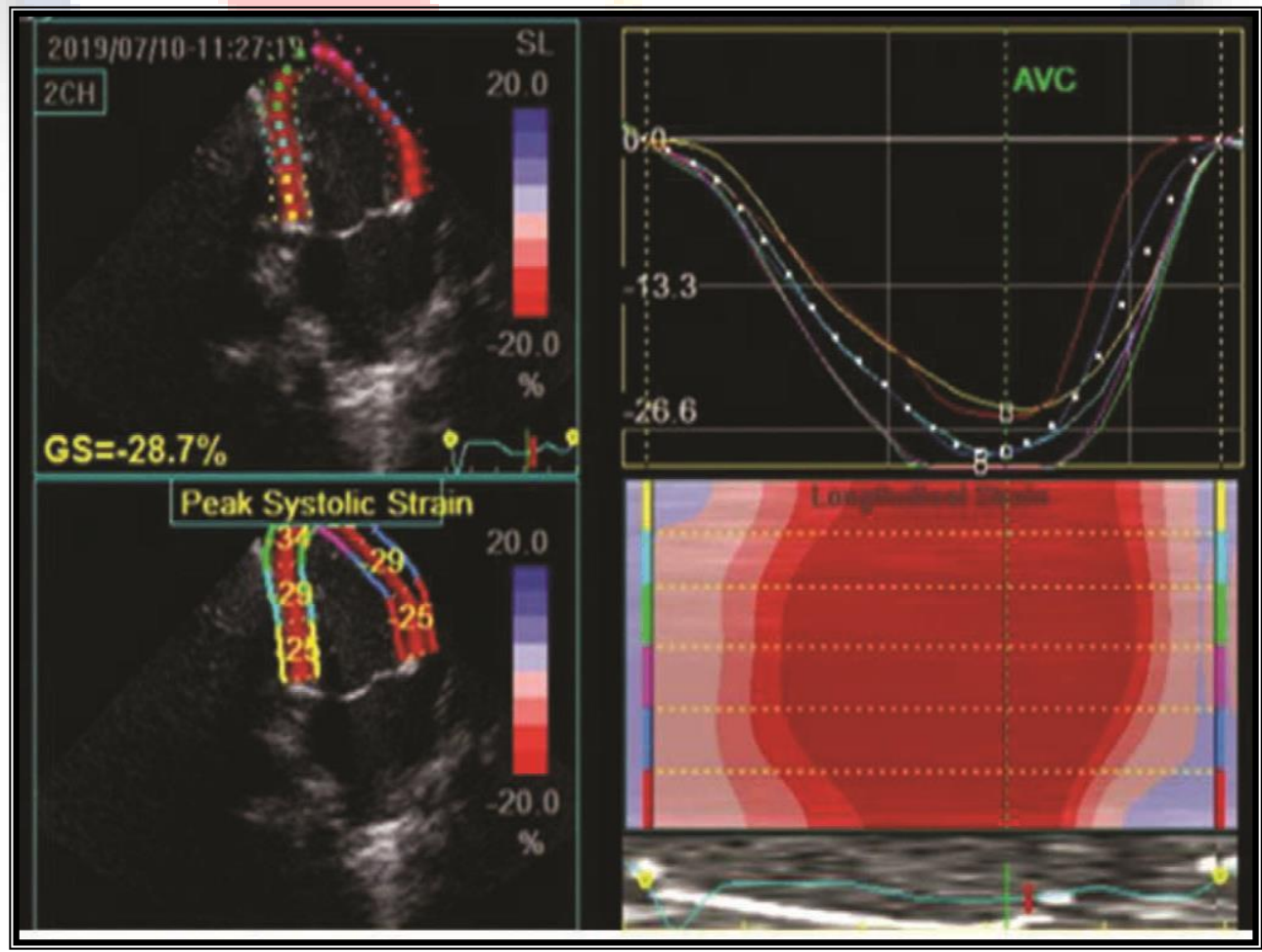

Figure (0): After: - $28.7 \%$ 


\section{DISCUSSION}

It was found that early shunt closure in congenital heart diseases will lead to reversal of elevated pulmonary artery systolic pressure, so, we should assess reversibility at early stage (Hoeper et.al.2013). Early detection of window of reversibility can be assessed clinically and by measuring heamodynamics (Chiu et.al.2011) currently, catheter is the only diagnostic and prognostic method to evaluate pulmonary hypertension.

Strain is calculated from percentage of change in length between two points before and after movement. It supplies a noninvasive method to evaluate myocardial contractility (Pirat et.al.2006).RV strain can detect early myocardial changes and predict its prognosis (Choi et.al.2015).

The studied patients showed female as a majority which agrees with (Ariane et al. 2007) who reported that there were significantly more females in the adult and pediatric CHD populations. In addition, our mean age was $37.3 \pm 7$ years, which agrees with (Botto et.al.2003) who reported that when all CHD lesions were considered, there have been more adults than children with CHD since 1985.

We found that majority of cases were ASD 14 (14.6\%) that consists with (Ariane et al. 2007) who found that ASD was the most common congenital lesion in adults.

In this study the defect size mean $16.8 \pm 3.6 \mathrm{SD}$ which consists with (Yang et.al.2015) who reported that the incidence of spontaneous closure was inversely related to size of the defect, and a higher possibility of spontaneous closure can be observed in defects less than $2.85 \mathrm{~mm}$. On the contrary, spontaneous closure rarely occurred in patients with defects more than $5.2 \mathrm{~mm}$.

In this study, QP/QS mean 2.6 $\pm 0.4 \mathrm{SD}$ which agrees with (Yang et.al.2015) who reported that spontaneous VSD closure likely to happen in patients with $\mathrm{Qp} / \mathrm{Qs}<1.53$; conversely, spontaneous VSD closure rarely happened in patients with Qp/Qs > 2.12. 
The defect size showed significant increase in Group I as compared to Group II $(\mathrm{P}<0.001)$. Which agrees with

(Recalde et.al.2010)who found that the larger the size the defect leads to increase the severity of pulmonary hypertension that results in irreversibility But disagree with (Kulik et.al.2012) who found that People with a big ASD and large left-to-right shunt may develop PVO

The QP/QS showed significant increase in Group I as compared to Group II $(\mathrm{p}=0.003 *)$. Which agrees with (D'Alto et.al.2012), who found that with increased degree of shunting are at greatest risk. But disagrees with (Kulik et.al.2012) who found that high pulmonary flow can be associated with normal PAP and that can be explained by that the lung is generally more flowophilic than flowphobic.

The LVEF showed significant increase in reversible cases after catheter closure. Which agrees with (Kumar et.al.2019) who found a detectable change in LV function every follow-up with biggest change at 3 months. However, disagrees with (Eroglu et.al.2013) who measured EF before closure and 24h and 1 month after closure, and found that LVEF increased suddenly in the first day then decreased back to normal

For the RV dimensions: there is significant increase in RVFAC in reversible cases after catheter closure. Which, agrees with (Islamlı et.al.2013) that found that after closure RVFAC significantly increased comparing to before closure. But disagrees with (Eroglu et.al.2013) as Right ventricular fractional area change (RVFAC) represent the ratio between end-diastole and end-systole so after closure of left-to-right shunt RVFAC decrease due to the decrease in RV diameters significantly

TAPSE showed non significant increase in reversible cases after closure. Which agrees with, (Balc1 et.al.2015) Demonstrated that TAPSE remained unchanged. They attributed that to the anatomical complexity of the right ventricle, difference in orientation of myocardial fibers, and reduced wall thickness may play a role in this result. But disagrees with (Chen et.al.2015) demonstrated that 
(TAPSE) reduced significantly after closure, which may be due to the less volume overload of the RV.

PASP showed significant decrease in reversible cases after interventional closure. Which agrees this is in agreement with (Chen et.al.2015) who reported similar results, and explained it that after closure, of the shunt, hemodynamic abnormalities were corrected and the diastolic blood flow velocity at the tricuspid valve orifice and the systolic blood flow velocity at the pulmonary valve orifice decreased,. Our results disagree with (Zwijnenburg et al. 2017)who found that some patient had an increase in pulmonary pressure due to LV diastolic dysfunction.

There was a significant increase of $\mathrm{S}_{\mathrm{RV}}$ in Group II versus Group I post closure ( $\mathrm{p}<0.001$ ). That consists with (Islamli et.al.2013) who found that in the patient group Color Tissue Doppler parameters and derivatives significantly increased after closure. However, disagrees with (Akula et.al.2016) reported that RV systolic velocity, tricuspid (S') decreased significantly after ASD catheter closure. He explained it that the increased preload in right ventricle had high basal RV systolic function following Starling's law of the heart because the $\mathrm{S}^{\prime}$ is load dependent parameter and significant decrease post-ASD closure resulting in RV systolic dysfunction.

After closure, we detected a significant increase of the longitudinal RV strain. Which agrees with (Moradian et.al .2018) who demonstrated that peak RVLS was shown to be significantly increasing post closure of ASD, explained by reverse remodeling effect of ASD correction on RV.But disagrees with (Kumar et.al.2019)who found that There was significant decrease in RV global longitudinal strain after 2days of ASD correction and decrease to near normal values at 3 months of correction.

variables correlated with RVLS strain was negatively correlated with the defect size $(\mathrm{r}=-0.65 ; \mathrm{p}=<0.001), \mathrm{Qp} / \mathrm{Qs}(\mathrm{r}=-0.53, \mathrm{p}=<0.001)$, PASP $(\mathrm{r}=-0.8, \mathrm{p}=$ $<0.001)$. 
On other hand, It showed significant positive correlation with S RV $(r=0.37$; $=<0.001)$ RVFAC $(r=0.30,<0.001)$, TAPSE $(r=0.34,<0.001)$. Which agrees with (Meris et.al.2018) who found that There were good correlations between global RVLS and TAPSE $(r=0.33, P<.001)$ and between global RVLS and RV FAC $(r=0.43, \mathrm{P}<.001)$ and SRV $(\mathrm{r}=0.38, \mathrm{P}<.001)$ in the study population and this can be explained by improvement of right ventricular function and increased RVLS is associated with improvement of other RV function parameters like TAPSE,RVFAC, $\mathrm{S}_{\mathrm{RV}}$

ROC curve analysis revealed that the RVLS value of -20 could predict reversibility of PASP with AUC 0.9 suggesting strong accuracy $(\mathrm{P}<0.001)$. RVLS correctly identify simple shunt patients with increased PASP (sensitivity $80 \%$ ), and it correctly reports $85 \%$ of simple shunt patients without increased PASP as true negatives, while $15 \%$ are incorrectly identified as false positive with specificity 85 Which agrees with (Meris et al.2018) who found that RVLS cutoff value was $\geq-19 \%$, with sensitivity of $95 \%$ and specificity of $85 \%$.

The logistic regression analysis detected that the RVLS ,RVFAC, SRV were independent predictors of reversibility of pulmonary hypertension $(\mathrm{P}<$ 0.05).Which agrees with (Meris et al.2018) who reported that by Using TAPSE and RV FAC as reference methods, speckle tracking-derived strain commonly identified reduced global RV function and that a global RVLS cutoff value of $\geq$ $19 \%$ is considered a valid method of differentiating normal and impaired right ventricles. Despite that TAPSE and RV FAC have a number of intrinsic limitations, but they are commonly used in clinical practice as indices of global RV contractility.

\section{CONCLUSION}

The RVLS value of $\geq-20$ could predict reversibility of PASP with AUC 0.9 suggesting strong accuracy $(\mathrm{P}<0.001)$. RVLS correctly identify simple shunt patients with increased PASP (sensitivity $80 \%$ ), and it correctly reports $85 \%$ of simple shunt patients without increased PASP as true negatives, while $15 \%$ are 
incorrectly identified as false positive with specificity $85 \%$. The RVLS ,RVFAC

SRV, were the independent variables predicting reversibility of PAH.Percutaneous closure of simple cardiac shunt leads to an immediate and striking remodeling process, reflecting a homogeneous pattern and time kinesis within the RV myocardium.

\section{Disclosure of potential conflicts of interest: None.}

\section{REFERENCES}

- Akula VS, Durgaprasad R, Velam V, Kasala L, Rodda M and Erathi HV. Right Ventricle before and after Atrial Septal Defect Device Closure. Echocardiography. 2016;40(1):783-6

- Ariane J. Marelli, MD; Andrew S. Mackie, MD, SM; Raluca IonescuIttu, MSc; Elham Rahme, PhD; Louise Pilote, MD, MPH, PhD. Congenital Heart Disease in the General Population Changing Prevalence and Age Distribution Circ. 2007;11(5):163-9.

- Balci KG, Balc MM, Soy MMAGB, Yilmaz S, Ayturk M, Dogan M, Yeter $\mathrm{E}$ and Akdemir R.Remodeling process in right and left ventricle after percutaneous atrial septal defect closure in adult patients. Türk Kardiyol Dern Arş. Arch Turk Soc Cardiol 2015; 43(3):250-5

- Botto LD,Correa A.Decreasing the burden of congenital heart anomalies: an epidemiologic evaluation of risk factors and survival. Prog Pediatr Cardiol. 2003; 1(8):111-5.

- Chen, Liang, Bai, Yuan, Wang, Fei-Yu. Transcatheter Closure of Atrial Septal Defects Improves Cardiac Remodeling and Function of Adult Patients with Permanent Atrial Fibrillation. Chinese medical journal $2015 ; 128(6): 780-8$. 
- Chiu JJ, Chien S. Effects of disturbed flow on vascular endothelium: pathophysiological basis and clinical perspectives. Physiol Rev 2011; 9(1):322-8.

- Choi SW, Park JH, Sun BJ. Impaired two-dimensional global longitudinal strain of left ventricle predicts adverse long-term clinical outcomes in patients with acute myocardial infarction. Int J Cardiol 2015; 19(6):165-9.

- Crystal H, Matthew A,Vincent N, Julie A. Atrial Septal Defect Device Closure in the Pediatric Population: A Current Review. Current Pediatrics Reports 2015; 3(3):231-7.

- D'Alto M. and Vaikom S. Mahadevan B. Pulmonary arterial hypertension associated with congenital heart diseaseEur Respir Rev 2012;21(126):330-4

- Eroglu, E., Cakal, S. D., Cakal, B. Time course of right ventricular remodeling after percutaneous atrial septal defect closure: assessment of regional deformation properties with two-dimensional strain and strain rate imaging. Echocardiography 2013; 30(3):324-7.

- Hoeper MM, Bogaard HJ, Condliffe R. Definitions and diagnosis of pulmonary hypertension. J Am Coll Cardiol 2013;6(2):42-8.

- Islamlı1 A, Cüms K,Bilgin M.Trans catheter Closure of Atrial Septal Defect and the Effects on Right Ventricular Function; Strain and Strain Rate Echocardiography JACC 2013;62(18):26-9.

- Kulik TJ. Pulmonary blood flow and pulmonary hypertension: Is the pulmonary circulation flowophobic or flowophilic? Pulm Circ 2012; 2(3):30-3.Van der Feen DE, Bartelds B, de Boer RA. Pulmonary arterial hypertension in congenital heart disease: translational opportunities to study the reversibility of pulmonary vascular disease. Eur Heart J 2017; $3(8): 20-5$. 
- Kumar P, Sarkar A, Kar SK. Assessment of ventricular function in patients of atrial septal defect by strain imaging before and after correction. Ann Card Anaesth 2019; 22(7):410-6.

- Meris A, Faletra F, Conca C. Timing and magnitude of regional right ventricular function: a speckle tracking-derived strain study of normal subjects and patients with right ventricular dysfunction. J Am Soc Echocardiogr 2018;2(3):823-31.

- Moradian M, Daneshamooz H, Shojaeifard M, Ghadrdoost B, Langeroudi HM, Khorgami MR. Echocardiographic right ventricular deformation indices before and after atrial septal defect closure: A scomparison between device and surgical closure. Res Cardiovasc Med 2018; 7(9):520-7.

- Pirat B, McCulloch ML, Zoghbi WA. Evaluation of global and regional right ventricular systolic function in patients with pulmonary hypertension using a novel speckle tracking method. Am J Cardiol 2006; 9(8):700-5.

- Recalde AS, Oliver JM,Galeote G. Atrial Septal Defect with Severe Pulmonary Hypertension in Elderly Patients: Usefulness of Transient Balloon Occlusion. Revista Española de Cardiología 2010;63(7):860-3

- Simonneau G, Montani D, Celermajer DS. Hemodynamic definitions and updated clinical classification of pulmonary hypertension. Eur Respir J 2019;5(3):180-6

- Van Riel AC, Schuuring MJ, van Hessen ID. Contemporary prevalence of pulmonary arterial hypertension in adult congenital heart disease following the updated clinical classification. Int J Cardiol 2014; 17(4):300-5.

- Yang Xu, Jinxiang Liu, Jinghua Wang, Min Liu, Hui Xu, Sirui Yang. Factors influencing the spontaneous closure of ventricular septal defect in infants Center of Pediatrics, Institute of Pediatrics, First Affiliated 
Bethune Hospital, Jilin University, Changchun 130021, China Int J Clin Exp Pathol 2015;8(5):614-8

- Zwijnenburg R.D., Baggen, M. Witsenburg, J.W. Roos-Hesselink, A.E. Prediction of pulmonary hypertension long-term after atrial septal defect closure, Eur Heart J 2017;38(1):493-6 